\title{
Evaluation of the investment process in the region and the influence of social well-being of the population on it
}

\author{
Galina Gratsinskaya ${ }^{1, *}$, Vladislav Levizov ${ }^{1}$ and Vladislav Kovalev ${ }^{1}$ \\ ${ }^{1}$ State Institute of Economics, Finance, Law, and Technology, Roschinskaya 5, Gatchina, Russia \\ 188300
}

\begin{abstract}
The authors of the present paper consider the main indicators for assessing the investment process in the region. The influence of effective human capital on this process is substantiated. The paper shows that the formation of such human capital in modern Russia depends on the social well-being of the population of the region, which in its turn is largely determined by the existing level of social justice. The Lorentz curves, the Gini coefficient and the Robin Hood index are proposed to be used for objective assessment of this level. In order to create more favorable conditions for the formation of effective human capital in the region, it is proposed to use progressive taxation and state social transfer payments, create and develop institutions of civil society, increase the investment activity of private business, the state and public-private partnership.
\end{abstract}

\section{Introduction}

The investment process in the region is a weakly structured and complex system [1]. In this regard, a comprehensive assessment of the investment process state should include, in one respect, a set of indicators (attributes) that characterize the system from different perspectives, and in another respect - a unified indicator characterizing the integrity of the system. The following terms can be used as indicators (attributes) reflecting the investment process in the region: volume of investments; growth rates of specific investments; value of specific investments; increase in gross regional product (GRP); economic efficiency of investments and other indicators [2].

In addition, the significant influence on the investment process of a number of factors and the associated indicators of the socio-economic system, under which the investment process takes place, should be taken into account for assessment. Such a complex phenomenon as the investment process is difficult to reflect in the form of a single indicator, which comprehensively characterizes it. One of the methodological approaches for a comprehensive assessment of the investment process is the comparison of the studied process as a whole with a reference investment process that has, for instance, average values of the main indicators in the selected set of regions [3]. In the region, it is viable to

\footnotetext{
* Corresponding author: Gracinskaya@mail.ru
} 
select complex indicators that determine investment activity, investment attractiveness and comparative favorableness of the investment climate. Complex indicators reflect the investment process in general and include the influence of the majority of indicators that characterize the investment process from different perspectives. The interrelations between these indicators are shown below in Figure 1.

\section{Materials and methods}

To elaborate investment programs for the development of the economy of the region under study and to identify possible and prospective "growth points" or clusters in it, it is necessary to imagine its development in the overall economy of the country's regions. The most complete characteristic of the ongoing investment processes in the constituent entities of the Russian Federation is the comparative favorableness of the investment climate [4].

The investment climate is a generalized characteristic of the entirety of ecological, social, economic, legal, political, organizational conditions that predetermine the potential and viability of investing to a particular economic system [5].

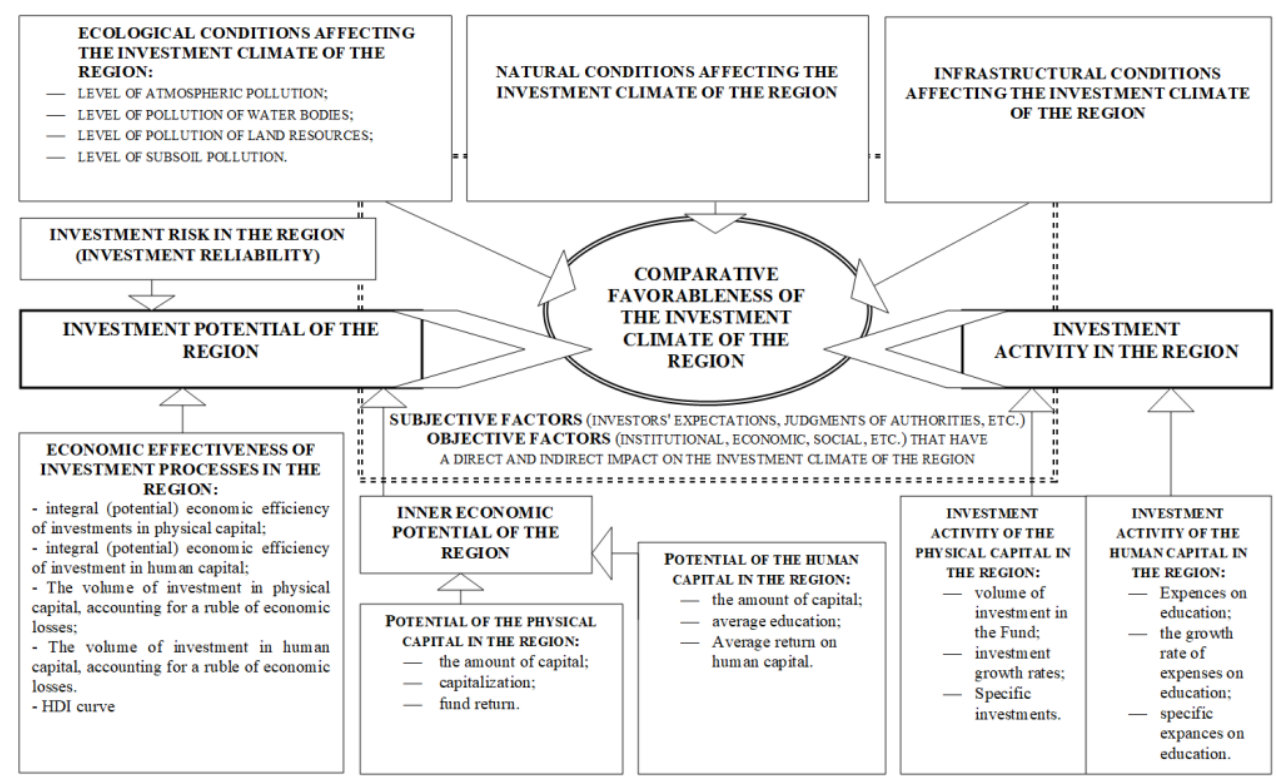

Fig. 1. Scheme of interrelations of indicators influencing comparative favorableness of the investment climate in the region.

The investment climate generally depends on investment activity, investment potential of the region, as well as on a set of other factors. At the same time, investment activity in the region implies the development and intensity of investment activity, characterized by the volumes and rates of attracting investments to the region.

The investment potential of the region is a system or a combination of various objective attributes, means and opportunities of the region that ensure the maximum attraction of investments.

The quantitative estimation of the index of the region's investment potential (IP) can be determined using the formulas (1) and (2). 


$$
\begin{gathered}
I P=\sqrt{\sum_{i=1}^{4} k_{i}^{2}} \\
\mathrm{k}_{\mathrm{i}}=\sqrt{\sum_{\mu=1}^{\mathrm{mi}}\left[\frac{\mathrm{p}_{\mathrm{i}, \mu}}{\mathrm{p}_{\mathrm{cp}, \mathrm{i}}}\right]^{2}}
\end{gathered}
$$

In formulas (1) and (2), there are used:

- complex coefficient characterizing the economic efficiency of investment processes in the region $(\mathrm{k} 1)$;

- complex coefficient characterizing the potential of the physical capital of the region (k2);

- complex coefficient characterizing the potential of the human capital of the region $(\mathrm{k} 3)$;

- ratio of the rank of investment reliability of the region to the value of the rank of investment reliability nationwide in Russia $(\mathrm{k} 4)$.

- number of indicators used in calculations of complex coefficients (mi);

- designation of indicators characterizing the complex indicator being calculated (pi, $\mu$ );

- indices $i, \mu$ to indicate the initial (primary) indicators used in calculating the values of complex indicators.

The calculations of investment potential have shown that the Leningrad Region ranks 20th among the constituent entities of Russia, St. Petersburg ranks 4th, trailing the Tyumen region, Moscow and the Moscow region [6].

To quantify the indicator of investment activity in the region (IA), a complex coefficient is also used, the quantitative value of which is determined by formulas similar to formulas (1) and (2), using the relevant indicators shown in Figure 1. By this indicator, the Leningrad Region ranks 14th, and St. Petersburg ranks 5th among the constituent entities of the Russian Federation.

The most complete characteristic of investment processes in the constituent entities of the Russian Federation is the comparative favorableness of the investment climate. To quantify this concept, complex indicators are used that characterize:

- investment potential;

- investment activity in the creation of physical capital;

- investment activity in the creation of human capital.

These components of the investment climate in their turn depend on the state of the climate, or in other words, there are correction retractions between them. At the same time, the state of the investment climate ultimately determines the investor's decision on investing his funds. Therefore, the most acceptable way to manage investment processes in the region is to create a favorable investment climate.

For calculations of the complex indicator used for comparative analysis of the favorable investment climate in different regions of Russia, the same approach is applied when calculating the indicators of investment potential and investment activity of the region.

The performed calculations show that the Leningrad Region ranks 17th among the constituent entities of the Russian Federation, and St. Petersburg is in the 6th place by the comparative favorableness of the investment climate. The analysis of the factors determining the lower place of Leningrad region by the favorableness of investment climate showed that the reason is the low investment activity of the region's human capital, which is conditioned by the following reasons:

1. Insufficient allocation of funds for education of the population of the region, which leads to a decrease in the potential of human capital and its activity. 
2. Low rates of growth in expenses on education and the values of the specific expenses on education compared with the average rates for Russia.

3. Smaller return from human capital activity than the average for Russia.

At the same time, the favorable investment climate in the region allows attracting additional investment, both in physical and human capital. However, the volume of investment is determined not only by the degree of favorable investment climate in the region, but also by social and economic policies.

Analysis of the essence of investment processes shows that one of the main factors in the formation of effective investment processes is the creation of effective human capital in the region [7]. At the same time, human capital of the region implies effective human capital that ensures the comprehensive functioning of the available physical capital and contributes to the improvement of this capital. Effective human capital is capable of selfdevelopment and an increase in the rate of return from it, which makes it advantageously different from physical capital.

Famously, the formation of effective human capital is determined by the quality of education, the health of the economically active population, its social well-being and a number of other factors. The influence of the most important factors on the formation of effective human capital in the region becomes relevant to study. One of such hard-toformalize and consequently insufficiently investigated factors is the social well-being of the human capital functioning in the region. Let us consider how social well-being is formed in the society and what conditions should be provided for its formation.

\section{Results}

On the basis of the analysis of scientific developments, the following main factors affecting social well-being of the population of the region can be pointed out:

1. Growth rates and absolute values of the growth of the gross regional product, since the amount of GRP per capita determines the economic possibilities of the state in the implementation of social programs. At the same time, to reflect the level of public welfare of the region, a well-known indicator named Human Development Index (HDI) can be used. The value of this indicator is calculated based on the life expectancy when a person is born, the level of education achieved and the annual income per capita.

2. Opportunities for redistribution of GRP to increase the funds used for science, culture, education, health, social policy and other sectors of the social sphere.

3. Positive dynamics of that part of revenue from the sale of products and services, which is invested in the development of human capital by the employers on their own initiative.

4. Efficiency of functioning of off-budget public funds and insurance systems based on the accumulative principle of the formation of social security sources.

5. Efficiency of using funds allocated to finance the social sphere.

The very concept of "social well-being" is rather comprehensive. In particular, it contains the idea of a person's place in the society, the attitude of members and institutions belonging to this society to him. At the same time, it is significant for a person to admit the justice of the existing relationships in society. The very idea of justice is contradictory. Generally, one can state that it is a correspondence of rights and duties, work and reward, crime and punishment for a person [8]. In economic science, justice is understood as equality of citizens in the distribution of a limited resource and primarily income. In this case, the most important complex indicator characterizing the social well-being of members of the society is the degree of satisfaction with income, taking into account the existing concepts in the economy in terms of social justice. Today, the existing socio-property 
stratification of the society became one of the most serious problems in Russia. For instance, $1 \%$ of the richest Russians account for $71 \%$ of the total personal assets in Russia.

The development of any socio-economic system depends not so much on economic parameters as on social ones. The reason is that the "human" factor is exactly the main factor that causes "accidental" deviations in the evolutionary development of socioeconomic systems. This phenomenon is called bifurcation. It indicates that the system can change the algorithm of its behavior being influenced by many factors (or their combination) of the external environment. In this regard, the level of social justice in the society can significantly affect the investment climate in the region. The Lorenz curves, the Gini coefficient and the Robin Hood index can be used as measures of the social justice level in the society. The Lorentz curve provides an opportunity to visualize both absolute equality in the income distribution within the society and the actual distribution of income among groups of the population, also reflecting the existing inequality over years. The conducted researches show that during the last decade there are scarce changes in the distribution of income between groups of the population of the Russian Federation [9]. In addition, the regions of the Russian Federation are also characterized by a high degree of society stratification on income received.

The Gini coefficient is quite informative to quantify the degree of inequality. The analysis of change in values of the Gini coefficient in the economy of St. Petersburg and the Leningrad Region within the period from 1996 to 2013 shows that the inequality between population groups in St. Petersburg is significantly higher than in the Leningrad Region.

The Robin Hood index is another numerical indicator of inequality in the distribution of income. It is equal to the share of total income, which should be redistributed to achieve equality of citizens in receiving disposable income.

These methodological approaches allow determining an approximate boundary where difference of the distribution of incomes in the society still serves as a motivation to the growth of the economy, but after which this difference is a factor of social tension in the state. Economic studies show that in most cases the value of the Robin Hood index is approximately $20 \%$ for a stable economy, where citizens have a high standard of living. Countries where the value of this index is higher have either an inefficient system of public consumption funds or an inefficient tax policy that does not allow the averaging of revenues. In the economy of Russia, the average value of the Robin Hood index is $30.2 \%$. At the same time, this index in the Leningrad Region is $27.3 \%$, in St. Petersburg - $32 \%$, in Moscow - 36.2\% [9]. This confirms the significant stratification of society in Moscow and St. Petersburg in terms of income. According to the Federal Tax Service of Russia for 2015, 427 citizens declared annual income of over 1 billion rubles, 613 people declared income from 500 million to 1 billion rubles, and 4,221 people - from 100 to 500 million rubles, even though the "average monthly" salary in Russia, according to the Federal State Statistics Service, was 33,925 rubles in 2015. [9].

To reduce the level of inequality of citizens in disposable income, it is recommended to apply mechanisms of progressive taxation and state social transfer payments in mature economies. Most countries have the so-called "progressive scale" of taxation. Country's citizens receiving low incomes pay low taxes. The rates of taxes are increasing with high incomes. The relevant state authorities should provide conscientious payment of income tax by citizens $[10,11]$.

\section{Discussion}

Social inequality in incomes inevitably leads to the increase in inequality in other areas. This inequality leads most significantly to the limitation of citizens' access to the following constitutional rights: 
1. Quality education, which results in phenomenon when children of wealthy parents study in "elite" schools and universities or in foreign educational institutions. Good education gives them the opportunity to occupy prestigious positions in the branches of power within the country.

2. Equipped sports complexes. Therefore, it is possible to keep and maintain good health, as well as the possibility of achieving high sports results.

3. Effective social security, both of the individual himself and of his family members.

At the same time, it is well known that the level of education, the state of health and the degree of social well-being are the basic factors for the formation of effective human capital in the society. Therefore, social inequality in society inevitably leads to disproportions in the development of human capital, which in turn lead to social tension in the society. Gradually, sufficiently isolated groups of the population are formed who consider themselves undeservedly deprived. They bring up protest moods, which can fade to open revolts in the future.

Besides the extreme forms of protest against social inequality, the established attitude to the education system as to the minimum standard ensured by the government have a deeper influence on the development of the country's economy. Such an attitude leads to the fact that sufficient measures of improving the education system are not taken. This situation does not contribute to the innovative development of the Russian economy and to the improvement of high-tech industries of the country's economy.

At the same time, targeted development of the country's human capital suffers from lack of attention, which ultimately leads to a lag in the development of this resource in comparison with the created production apparatus. This leads to void use of the already created physical capital as a whole. The opportunities to increase the rate of labor productivity expand consequently disappear, even with a modified production apparatus. The main cause of social inequality in modern Russia is the unfair solution of the issue of property distribution. Another reason for the persisting inequality is the high level of corruption.

\section{Conclusion}

The main way to solve this problem is to create and develop civil society institutions promptly. In conjunction with the above, it is necessary to increase dramatically the investment activity of private business, the state and the private-and-state partnership in order to create new industrial enterprises instead of obsolete ones. At the same time, there is a need to invest all the available resources into development of the economy, paying special attention to the modernization of industry, agriculture, introduction of new technologies. Such an approach can allow achieving accelerated development of the country's economy.

\section{References}

1. G.V. Gratsinskaya, V.F Puchkov, Zhurnal pravovykh i ekonomicheskikh issledovaniy 2, 133-137 (2016)

2. A. Larionov, MATEC Web of Conferences 170, 01103 (2018)

3. A. Larionov, L. Metechko, A. Davydov, D. Davydov, MATEC Web of Conferences 193, 04027 (2018)

4. A. Bukreev, O. Vasilyeva, V. Vlasenko, E. Sizova, MATEC Web of Conferences 106, 08034 (2017) 
5. E. Nezhnikova, Procedia doi.org/10.1016/j.proeng.2016.11.854

Engineering

165

(2016)

6. A.K. Orlov, I.Y. Chubarkina, MATEC Web of Conferences 106, 08015 (2017)

7. I.V. Ilin, A. Lepekhin, A.I. Levina, O.Yu. Iliashenko, Advances in Intelligent Systems and Computing 692, 1306-1314 (2018) doi:10.1007/978-3-319-70987-1_138

8. I.G. Lukmanova, M.Y. Mishlanova, International Journal of Economics and Financial Issues 5, 208-216 (2015)

9. L.N. Nikolova, D. G. Rodionov, M.A. Bahauovna, International Journal of Economics and Financial, 6(2), 246-252 (2016)

10. A. Mottaeva, MATEC Web of Conferences, 170, 01053 (2018) doi:10.1051/matecconf $/ 201817001053$

11. A. Mottaeva, A. Zheltenkov, MATEC Web of Conferences, 170, 01022 (2018) doi:10.1051/matecconf/201817001022 